- LuyIII

- Registrarse

- Buscar

- Actual

- Archivos

- Anuncios

- G.CLAVES

- FHCE

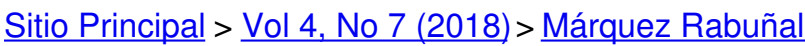

Internacionalismo e inicio de las políticas de drogas en Uruguay. Montevideo y el mundo atlántico, 1912-1930

Adrian Márquez Rabuñal

Resumen

El estudio del origen de las políticas de drogas con un enfoque global viene concitando un creciente interés académico. También se ha propuesto que es necesario avanzar hacia una nueva historia de las drogas de América Latina. Dentro de los fenómenos globales y más específicamente del mundo atlántico que influyeron en las primeras acciones dirigidas al control de drogas en Uruguay se encuentra el internacionalismo de principio del siglo XX. Al mismo tiempo la emergencia del uso recreacional de morfina y cocaína fue visto por las elites del país como la aparición de una costumbre exótica. Este ensayo explora el nacimiento de las políticas de drogas en Uruguay buscando iluminar como se combinaron las iniciativas locales con el impulso internacional.

Texto completo:

PDF

DOI: http://dx.doi.org/10.25032/crh.v4i7.212

\section{Enlaces de Referencia}

- Por el momento, no existen enlaces de referencia

\section{Convocatorias para los próximos Temas Centrales}

\section{№ 8 (primer semestre 2019)}

Mundos del trabajo y clases trabajadores en los siglos XIX y XX: nuevas perspectivas y aproximaciones

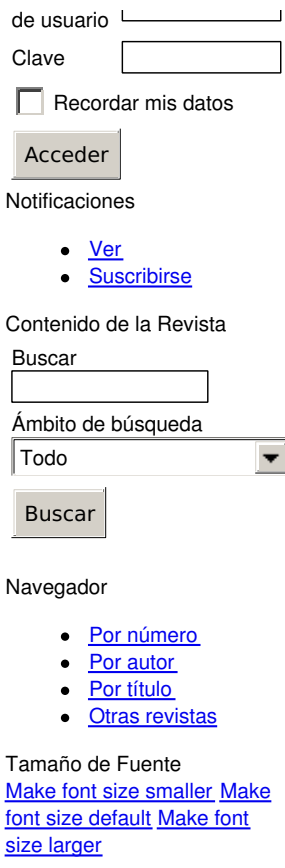

See more of Paseo De Inicio De Año on Facebook. Log In. or. Create New Account. See more of Paseo De Inicio De Año on Facebook. Log In. Forgotten account? \#RetoTravis en comunidad de El Centenario \#BCS Camara abordo comparativa de \#GoPro vs Camara \#GarminVirbXE vídeo de Gopro propiedad de XF Photographie bike excelente paseo y excelente vídeos de inicio de año y quiero regresar este fin de semana a recorrerla de nuevo! Paseo De Inicio De Año shared XF Photographie bike's post. 15 de Marzo de 1939 Desde tratados hasta países Septiembre de 1939 ¿Quién es responsable de la Guerra? Destruccion de Checoslovaquia Campaña contra Polonia Factores a tomar en cuenta Los problemas en Memel Ciudad de Memel (Klaipeda) estaba bajo domino del Consejo de Embajadores (ciudad libre) hasta 1923 donde es tomada por Lituania. Tras organizacion de diriguentes Nazis en la ciudad, y a la par con la entrada a Checoslovaquia, el gobierno Lituano entre Memel al gobierno Alemán. Polonia Hitler exige devolución de Danzig junto con un camino y ferrocarril que la

El dossier propuesto procura contribuir a la puesta en diálogo de investigaciones que una a Alemania. Polacos (J. Beck) aborden el mundo del trabajo desde diversas perspectivas metodológicas y temáticasAsí, los antiguos mexicanos se en la medida que todo proceso de ampliación de un campo de estudios exige luego esfuerzos de síntesis y lecturas comparativas. vieron unidos al inicio candente de la vida y concibieron la sexualidad como un regalo divino que habría de acompañarlos a lo largo de su historia. Mayas, zapotecas, 


\section{Cronograma para los envíos}

1ํ de marzo de 2019: Presentación de resúmenes a revistaclaves@fhuce.edu.uy (Diez líneas más 5 con CV)

15 de marzo: Comunicación de los editores de las propuestas aceptadas.

30 de abril: Envío por parte de los autores de los artículos completos para referato.

Leer más:http://www.revistaclaves.fhuce.edu.uy/index.php/Claves-

FHCE/article/view/209/217

№ 9 (Segundo semestre de 2019)

\section{Afrodescendencia, cultura y sociedad en el Cono Sur, $1760-1960$}

Coordinadores: Alex Borucki (Universidad de California, Irvine) y Florencia Thul (Universidad de la República, Uruguay)

Descargar texto de la convocatoria:

http://www.revistaclaves.fhuce.edu.uy/index.php/Claves-FHCE/article/view/228/242 mixtecas, nahuas... todos exaltaban a los dioses de En el principio era el sexo... y los dioses nahuas lo disfrutaban intensamente, tanto y con tanto vigor que originaron el universo. Así, los antiguos mexicanos se vieron unidos al inicio candente de la vida y concibieron la sexualidad como un regalo divino que habría de acompañarlos a lo largo de su historia. Mayas, zapotecas, mixtecas, nahuas... todos ex

Claves también recibe artículos sobre temática libre y reseñas bibliográficas, que cumplan con las normas de publicación señaladas por la revista. Los envíos se aceptan hasta el $1^{\circ}$ de marzo y $1^{\circ}$ de agosto para las respectivas ediciones semestrales.

Claves. Revista de Historia utiliza el software libre Open Journal System. Está indizada en el Catálogo Latindex y adherida al Digital Object Identifier (DOI). Integra la Asociación Uruguaya de Revistas Académicas (AURA).

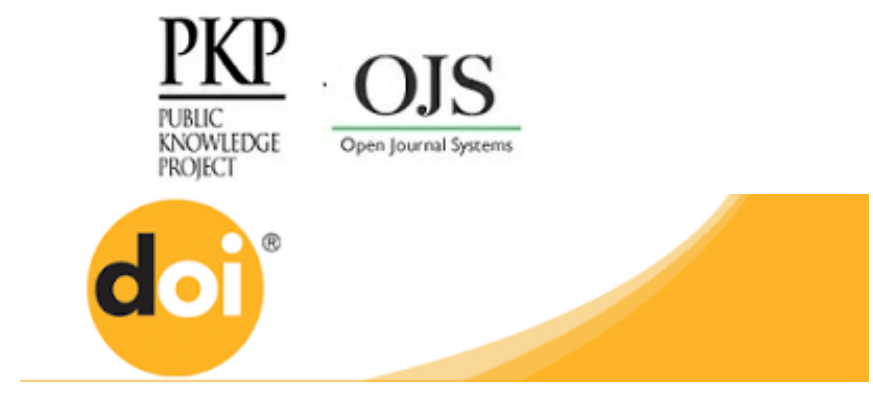

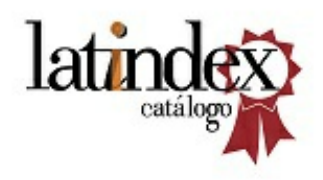

$$
\text { - } \begin{aligned}
& \text { Facultad } \\
& \text { de Humanidades } \\
& \text { y Ciencias de la Educación }
\end{aligned}
$$

Sus artículos se publican tras ser evaluados por especialistas externos mediante arbitrajes por "pares ciegos".

revistaclaves@fhuce.edu.uy 
